well as a technical one. Hitherto, economic sustainability has been a crucial weakness in the argument for NHSnet, because a series of decisions about the design of the network led to the risk of "lock in" and obsolescence.

\section{Conclusions}

The elements of the user requirement outlined here are interlinked: the best technical solution, now and in the future, must make sense economically and provide the required security and reliability. The NHS Executive has recognised that NHSnet in its original form was neither "modern and dependable" ${ }^{20}$ nor the most appropriate or cost effective solution available and now seems to be more open to discussion of the merits of alternative approaches. Perhaps we can now move to a more considered debate about future networking options.

We thank the NHS Information Authority for the data on NHSnet and to Demon Internet for their data. We thank staff at the NHS Executive, NHS Information Authority, members of the $B M J$ editorial committee, and anonymous referees for comments on earlier drafts.

The NHS Information Authority's response to the authors' request about open access government can be found at www.kingsfund.org.uk/ehealthsystems/html

Competing interests: None declared.
1 Anderson R. Clinical system security: interim guidelines. BMJ 1996;312:109-11.

2 Mitchell P. Go with the flow [IT update]. Health Sero J 2000 Mar 16:16. Department of Health. Information management and technology strategy. London: DoH, 1992.

NHS Executive. Information for health. Leeds: NHS Executive, 1998

5 Denham J. House of Commons official report (Hansard). 1999 Apr 30: col 279.

6 National Audit Office. The 1992 and 1998 information management and technology strategies of the NHS Executive. London: Stationery Office, 1999. (HC 371, session 1998-99.)

7 Committee of Public Accounts. The 1992 and 1998 information management and technology strategies of the NHS Executive. London: Stationery Office, 2000. (HC 406, session 1999-2000.)

8 Barua A, Lee B. An economic analysis of the introduction of an electronic data interchange system. Information Syst Res 1997;8:398-422.

9 Lee M. Internet-based financial EDI: towards a theory of its organisational adoption. Comput Networks ISDN Syst 1998;30:1579-88.

10 Center for Next Generation Internet. Internet Trends. www.ngi.org/ trends.htm (updated $13 \mathrm{Feb} 2000$ ).

11 Cabinet Office. Modernising government. London: Stationery Office, 1999. (Cm 4310.)

2 Keen J. Rethinking NHS networking. BMJ 1998:316:1291-3.

13 Anderson R. Clinical systems security interim guidelines. BMJ 1996;312: 109-11.

14 Roscoe T, Wells M. NHSnet-learning from academia. BMJ 1999;318: $377-9$.

15 Audit Commission. Ghost in the machine: an analysis of IT fraud and abuse. London: Stationery Office, 1998

16 NHS Executive. NHS code of connection. Version 1.0. NHS Executive: Leeds, 1999.

17 Borowitz S, Wyatt J. The origin, content, and workload of e-mail consultations. JAMA 1998;280:1321-4.

18 Wood FB, Cid VH, Siegel ER. Evaluating internet end-to-end performance: overview of test methodology and results. J Am Med Inf Assoc 1998;5:528-45.

19 Bingham CM, Higgins G, Coleman R, Van der Weyden MB. The Medical Journal of Australia internet peer-review study. Lancet 1998;352:441-5.

20 Department of Health. The new NHS: modern, dependable. London: Stationery Office, 1998.

(Accepted 14 June 2000)

\title{
NHSnet in Scottish primary care: lessons for the future
}

Madeleine Willmot, Frank Sullivan

Editorial by Kelly

Forth Valley Health Board, 33 Spittal Street, Stirling FK8 1DX

Madeleine Willmot clinical effectiveness coordinator

continued over

BMJ 2000;321:878-81

\section{bmj.com}

Extra tables giving further details of results appear on the BMJ's website. This article is part of the BMJ's trial of open peer review, and documentation relating to this also appears on the website

\section{Abstract}

Objective To evaluate the primary care communications initiative, which introduced NHSnet to primary care in Scotland.

Design Semi-structured telephone interviews, postal questionnaire.

Setting All 15 Scottish health boards, random sample of 1 in 3 of all Scottish general practices.

Participants Information management and technology managers of health boards, 355 practice managers in the general practices.

Main outcome measures Variations between health boards in styles of project management, means of connection to NHSnet, costs to general practices, and training provided. Practices' levels of participation in initiative, initial use of NHSnet, and factors acting as incentives and disincentives to use of NHSnet.

Results $99 \%$ of Scottish general practices agreed to participate in initiative. Health boards varied significantly in project management styles (from minimal to total control), the nature of the networks they established (intranets or direct connections), costs to practices (from nothing to $£ 125$ per general practitioner per year), and training provided (from none to an extensive programme). In $56 \%$ of practices someone accessed NHSnet at least once a week. Practices varied considerably in amount of internet training received and staff groups targeted and in the intention to provide desktop access to NHSnet through a practice network.
Conclusion The initiative has successfully introduced a network that links Scottish general practices, health boards, and hospital trusts. However local variation in this "national" initiative may affect its use in primary care. Health authorities and general practices in England and Wales may wish to note these findings in order to avoid unhelpful variation.

\section{Introduction}

NHSnet offers the prospect of an electronic network for primary care professionals across Britain. The new NHS Information Management and Technology Strategy, which is investing $£ 1 b n$ to improve patient care, ${ }^{1}$ and the plans for an electronic telecommunications infrastructure linking all UK general practices ${ }^{2}{ }^{3}$ should make this prospect a reality. This will benefit patients by reducing paperwork and speeding up access to laboratory results, hospital appointments, and referral and discharge letters through use of email. Perhaps more importantly, it will redress the traditional problem of poor access to library resources in primary care ${ }^{4}$ by providing access to up to date information through NHSnet web pages and the internet. ${ }^{56}$ With the current emphasis on evidence based practice ${ }^{7-10}$ and clinical governance, ${ }^{11}$ and the increasing amount of information that doctors must sift through to keep up to date, ${ }^{12-14}$ rectifying this problem has become a priority. ${ }^{45}$

However, since the plans for the electronic infrastructure were announced, Scotland has moved ahead of England and Wales on this issue. The English 
white paper suggested that it would be 2002 before all general practices were connected to NHSnet. ${ }^{3}$ The Scottish Office, on the other hand, launched its primary care communications initiative in April 1997. ${ }^{16}$ This offered all Scottish general practices a free computer, installation of an ISDN line, registration to NHSnet, and one day's training. ${ }^{5}$ Practices could not receive the free computer without agreeing to connect to NHSnet. ${ }^{18}$

Because of the intense interest in this issue in Scottish primary care and the fact that the Scottish experience might provide useful lessons for England and Wales, we decided to evaluate the primary care communication initiative at the end of 1998 , just over a year after it was launched and four months after it was considered complete. We explored the way in which it was implemented, identified initial levels of use of NHSnet, and assessed the impact of local variations.

\section{Participants and methods}

In our evaluation we conducted telephone interviews and a postal questionnaire. Both were piloted before use and minor changes made.

We conducted semi-structured telephone interviews with the individual (usually the information manager) in each of the 15 Scottish health boards who was responsible for local coordination of the initiative. These interviews were recorded, transcribed, and analysed based on categories that emerged from both the questions and responses. The interviews explored the level of health board involvement in implementing the initiative, the infrastructures put in place, costs to practices, and training provided.

We sent a questionnaire to the practice managers of a random sample of one in three of all Scottish general practices, stratified by health board $(n=355)$. The questionnaire asked about the practices' participation in the initiative, access to and levels of use of NHSnet, training received, and problems encountered.

We analysed the results using SPSS.

\section{Results}

We achieved $100 \%$ participation in the interviews and an $87 \%(308 / 355)$ response to the questionnaire, reflecting the high level of interest in this issue.

\section{Participation and initial use}

The response to the primary care communication initiative surpassed expectations, with 1053 (99\%) of the 1065 general practices in Scotland deciding to participate. The momentum generated by this initial enthusiasm seems to have led to promising initial levels of use of NHSnet: $203 / 299(68 \%)$ of respondents said they were now accessing NHSnet, and 174/308 (56\%) identified at least one member of the primary care team (a general practitioner in $47 \%$ of cases) who was using it at least once a week. This perhaps reflects the fact that $65 / 140(46 \%)$ of practices listed access to information via NHSnet as one of the main advantages of the initiative (see table).

\section{Coordination of the initiative}

While initial levels of involvement and use were encouraging, reaching this stage was a complicated process. Although this was a national initiative with a central project management team to coordinate its
Advantages of Scottish primary care communications initiative listed by 140 general practices

\begin{tabular}{lc} 
Advantages & $\begin{array}{c}\text { No (\%) of practices } \\
\text { listing this advantage }\end{array}$ \\
\hline Email facility & $78(56)$ \\
\hline NHSnet and internet access & $65(46)$ \\
\hline Connection with hospital trusts & $28(20)$ \\
\hline Connection with health board & $24(17)$ \\
\hline Free computer & $23(16)$ \\
\hline Word processor & $21(15)$ \\
\hline Other & $26(19)$
\end{tabular}

implementation, a lack of coherence emanated from a decision to devolve a degree of coordinating responsibility to the 15 Scottish health boards; a policy which has also been recommended in England. ${ }^{19}$

The roots of the problem were twofold. Firstly, the level of responsibility given to each health board by the project management team varied, with two health boards having minimal input and five taking almost complete control of implementation. The remaining eight formed a spectrum in between, from those that simply facilitated communication with general practices to those that demanded more input into coordination, prioritisation, and means of connection. Secondly, the health boards were allowed to make local decisions about key issues such as costs to practices and networking arrangements. These two factors introduced considerable local variation.

\section{Networking arrangements}

Area networks

Health boards varied in the way that they connected practices to NHSnet. Some created local intranets through which all practices were connected to NHSnet via a single access point (fig 1a). These intranets also incorporated health boards and hospital trusts. Others, finding the costs of maintaining an intranet prohibitive, established direct connections to NHSnet from each individual practice (fig 1b). At the time of the evaluation Shetland and Orkney health boards had provided their practices with access to email only.

This lack of a coherent infrastructure across Scotland made problems harder to deal with. For example, there were ongoing difficulties with computer connections to NHSnet, with $25(8 \%)$ of practices and $10(67 \%)$ of the health boards complaining about the instability of email connections. Three health boards also reported that some practices had received huge

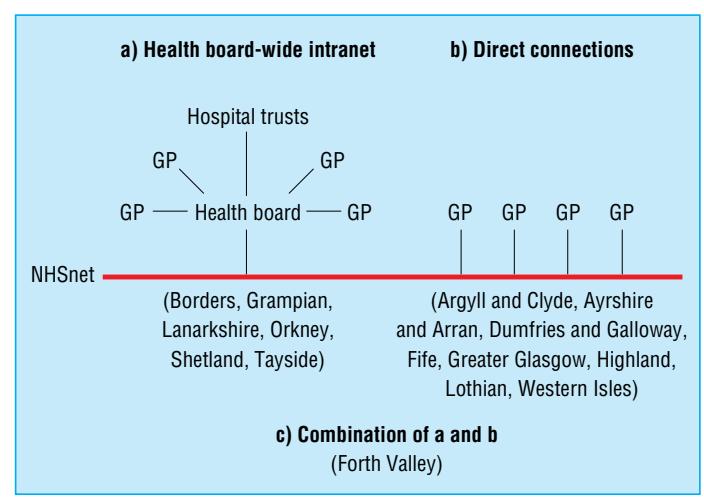

Types of network adopted by Scottish health boards to link general practices with NHSnet
Tayside Centre for General Practice, University of Dundee, Dundee DD2 4AD Frank Sullivan professor of research and development in primary care

Correspondence to: M Willmot madeleine. willmot@fvhb.scot. nhs.uk 


\section{Subjects covered by national training day on use of NHSnet}

Windows NT

- Client (such as NT environment, running programs, Explorer)

- Administration (such as security, user rights, archiving)

- Utilities (such as backup, printer management)

\section{MS Exchange}

- Client (such as address book, messages, attachments)

- Server (such as mailbox, profiles)

- Internet Explorer

- Anti-virus software stage may not have generated sufficiently large bills to have a negative impact. As bills escalate, practices that have to pay for calls may start to restrict use.

\section{Training}

Education is an important element of managing change. ${ }^{20}{ }^{21}$ This was taken into account on a superficial level during the implementation of the initiative by the provision of one day's training for one person from each practice (see box). This was provided at three main centres around Scotland, and representatives from about 790 practices attended. Unfortunately, this introduced further local variation as the distances involved meant that only half of the health boards were able to take full advantage of it. This arrangement discriminated against practices in the more remote areas despite recognition that rural areas need remote access to information more than most. ${ }^{22}$

Of those who did attend the training only 55/142 (39\%) found it useful. It focused on administration issues rather than use of the internet as an information resource. Thus, the opportunity to maximise use of the internet to support evidence based practice was missed. Indeed, only 15 minutes were spent on use of Internet Explorer. Because of the focus on administration issues, the 313 attendees were mainly practice managers $(143(46 \%))$ and office staff $(120(38 \%))$. Only $43(14 \%)$ were general practitioners, and eight $(3 \%)$ were practice nurses.

Variations in training were compounded by the fact that health boards were expected to provide more detailed training locally. All but two health boards (Highland and Western Isles) did so or planned to do so, but they differed in the range, amount, and type of training provided and in the staff groups they targeted (see extra table on BMJ's website). Despite the fact that nine health boards invited all members of the primary heath care team to their training, again it was usually the practice managers $(77 / 192(40 \%))$ and office staff (70 $(37 \%))$ who attended, whereas only $37(19 \%)$ attendees were general practitioners and eight $(4 \%)$ were practice nurses. This bias towards administrative staff meant that, although 10 health boards provided training on use of the internet, this was not targeted at healthcare professionals. Interestingly, the practices of health boards that did provide internet training seemed more likely to make regular use of NHSnet (see extra table on BMJ's website), suggesting that targeting education at healthcare professionals might have a positive impact on use: at one extreme, only $20 \%$ of respondents in a health board that had provided no internet training were using NHSnet compared with $95 \%$ of respondents in a health board that had provided it.

These differences in national and local provision of training meant that some practices had less opportunity to develop their skills and knowledge than others. This is important since 88/178 (49\%) of practices felt that lack of training was a disincentive to using NHSnet.

\section{Discussion}

The Scottish primary care communications initiative has been successful in implementing a national network that links all Scottish general practices as well as most health 
boards and hospital trusts. The level of participation is high, and initial levels of use of NHSnet, while not overwhelming, are at least encouraging. Yet, although this initiative is to be welcomed as an important step forward for primary care, ${ }^{2}$ its implementation has been less than satisfactory.

Unfortunately health boards were given different levels of responsibility for implementation and were allowed to make local decisions on what should have been core issues. As a result, a highly variable system has emerged with inequalities in levels of use, networking arrangements, access to NHSnet, costs to practices, and availability of training. There is a now need to examine the infrastructure that has been created and consider ways of improving coordination so that the variations described here do not affect the future use of NHSnet across Scotland.

The variation in costs to practices highlights the dangers of allowing local decision making within a national initiative. As well as leading to discontent among those who have to pay, it will disadvantage some practices and may inhibit their use of NHSnet, a potentially valuable source of evidence for a specialty that has traditionally had poor access to information. ${ }^{4}$ This issue should be rectified to achieve consistency and fairness across Scotland.

Access to sources of evidence via NHSnet has obvious advantages ${ }^{23} 24$ and may be important for the future development of evidence based practice in primary care ${ }^{25}$ With clinical governance looming large, there is a need for progress in this area. ${ }^{11}$ Desk top access to the internet for all primary care professionals should be a priority, yet few general practices have provided this. The initial lack of internal networking we found may have been partly because of practices' lack of knowledge regarding the potential of NHSnet. This was undoubtedly compounded by the mixed messages from health boards as to whether internal networks were acceptable. This issue will probably resolve itself as concerns about security are reduced and understanding of the potential of desk top access to the internet increases.

Simply providing the necessary equipment to access to NHSnet is not enough; comprehensive, appropriate education targeted at the right individuals is also required to ensure that the potential of NHSnet to support evidence based practice is maximised. ${ }^{26}$ Health boards should take the opportunity now, while enthusiasm is still high, to redress imbalances in this area.

There are obvious lessons to be learnt from the implementation of the Scottish primary care communications initiative in relation to ensuring that future national projects avoid the introduction of local differences through effective central coordination. Moves are under way to make NHSnet available to general practices in England and Wales. ${ }^{5}$ Those coordinating the process should look to Scotland and learn from its experiences.

We thank Dr Malcolm McWhirter, director of public health, Forth Valley Health Board, for his support and encouragement. Invaluable assistance and advice was provided by Dave Simpson, information management and technology manager, and Mary Cameron, systems manager, Forth Valley Health Board. We also thank all those who participated in the evaluation.

Contributors: MW and FS designed the study. MW was responsible for data collection, processing, and analysis and writing the paper. FS provided supervision, advised on the

\section{What is already known on this topic}

Access to research evidence in primary care is traditionally poor, but the internet can address this by bringing up to date information into the consulting room

All general practices in Scotland have been offered access to NHSnet, but no evaluation had been made of its introduction or its impact on use of the internet

\section{What this study adds}

99\% of Scottish general practices are connected to NHSnet, but problems may arise through local variations in infrastructure, costs to practices, and training provided

$56 \%$ of practices use NHSnet at least once a week, but access can be difficult and training has not been targeted at healthcare professionals

There are organisational implications for those in England and Wales embarking on a similar exercise

process for data collection and analysis, and edited the paper. MW is the guarantor.

Funding: Supported by the Directorate of Public Health, Forth Valley Health Board.

Competing interests: MW is employed by Forth Valley Health Board.

1 Wyatt J, Keen J. The NHS's new information strategy. BMJ 1998;317:900.

2 Scottish Office Department of Health. The Scottish health service: ready for the future. Edinburgh: Scottish Office Department of Health, 1997.

3 Department of Health. The new NHS. London: HMSO, 1997.

4 Scottish Library and Information Council. Enabling access to the knowledge base of healthcare. Library and information provision for the NHS in Scotland. Edinburgh: Scottish Library and Information Council, 1998.

5 Scottish Health Care Supplies. National initiatives to promote primary care information management and technology. Information for health boards. Edinburgh: Scottish Health Care Supplies, 1997.

6 De Lusignan S, Brown A. Internet can be accessed from NHSnet. BMJ 1998:317:1319.

7 Davidoff F, Haynes B, Sackett D, Smith R. Evidence based medicine. BMJ 1995;310:1085-6.

8 Silagy C, Haines A, eds. Evidence based practice in primary care. London: BMJ Books, 1998

9 Sackett DL, Rosenberg JA, Muir Gray JA, Haynes RB, Richardson WS Evidence-based medicine: what it is and what it isn't. BMJ 1996;312:71-2.

10 NHS in Scotland Management Executive. Primary care: the way ahead. A discussion paper. Edinburgh: Scottish Office Department of Health, 1996.

11 Scottish Office. Designed to care. Renewing the National Health Service in Scotland. Edinburgh: Scottish Office Department of Health, 1998

12 Rosenberg W, Donald A. Evidence based medicine: an approach to clinical problem solving. BMJ 1995;310:1122-6.

13 Weed LL. New connections between medical knowledge and patient care. BMJ 1997;315:231-5.

14 Muir Gray JA. Where's the chief knowledge officer? BMJ 1998;317:832-40.

15 Glanville J, Haines M, Auston I. Getting research into practice. Finding information in clinical effectiveness. BMJ 1998;317:200-3.

16 Scottish Office Department of Health. Investment in primary care IME T. Preliminary briefing for health boards. Edinburgh: Scottish Office Department of Health, 1997.

17 Dunmore T. Primary care computer equipment launch. Edinburgh: Scottish Office Department of Health, 1997. (Letter to health boards.)

18 NHS Executive Information Management Group. NHS-wide networking. London: NHS Executive, 1995

19 NHS Telecommunications Branch. GP Practices-technical requirements for connection to, and use of, NHSnet. Birmingham: NHS Telecommunication Branch, 1997.

20 Atkinson C, Hayden K. Strategies for success. In: Change and teamwork in primary care. London: BMJ Books, 1993:16-23.

21 Broome A. Managing change. London: Macmillan, 1990.

22 Farmer J, Richardson A. Information for trained nurses in remote areas: do electronically networked resources provide an answer? Health Libraries Rev 1997;14:97-103.

23 Steiner BD, Reid A, Smucker DR. Developments on the internet: a prac tical guide for primary care physicians. Fam Med 1996;28:128-33

24 Westberg EE, Miller RA. The basis for using the internet to support the information needs of primary care. J Am Med Informatics Assoc 1999;6:6-25.

25 Kidd M, Purves I. Role of information technology. In: Silagy C, Haines A, eds. Evidence based practice in primary care. London: BMJ Books, $1998 \cdot 123-8$

26 Klercker T, Zetraeus S. Dilemmas in introducing world wide web-based information technology in primary care: a focus group study. Fam Prac 1998;15:205-10.

(Accepted 14 June 2000) 